\title{
The Differentiation and Analysis of Pivotal Construction and Similar Syntactic Constructions*
}

\author{
Zhiyan $\mathrm{Hu}$ \\ Faculty of Foreign Languages, Xinxiang Medical University, Xin Xiang, China
}

\begin{abstract}
Since the appearance of "pivotal construction", scholars have always questioned its existence and wanted to classify it into the category of other syntactic constructions. Therefore, it is necessary to make a more detailed distinction between the pivotal construction and the other similar syntactic constructions. Generally, the pivotal construction can be abbreviated as $N_{1}+V_{1}+N_{2}+V_{2}$, which is the same as in other syntactic constructions or sentence patterns: subject-predicate structure as the object construction, serial predicate construction, fused serial predicate and pivotal construction. In this paper, syntax combined with semantics, these four simple sentence patterns (syntactic constructions) are taken as examples and analyzed in detail. Finally, we draw a conclusion that $\mathrm{N}_{1}, \mathrm{~V}_{1}, \mathrm{~N}_{2}, \mathrm{~V}_{2}$ have complex relationship on the syntactic structure. Meanwhile, through the semantic analysis and classification of $V_{1}$, we make a clear distinction of $V_{1}$ in the four types of simple sentence patterns and the relationship between $V_{1}$ and $V_{2}$ is clearly differentiated.
\end{abstract}

Index Terms - pivotal construction, syntax, semantic, distinction

The pivotal construction, focus of this paper, is a special syntactic structure in Chinese, and it exists in the history since ancient times. The source can be traced back to the beginning of the written language. For instance, we can find a lot of pivotal constructions in the inscriptions on oracle bones (Zheng, 1996). However, modern grammar studies began to pay attention to this linguistic phenomenon from the middle of the last century. In the researching processes, there are always a lot of disputes over two issues, namely the category division and syntactic construction classification. This paper is aiming at finding out the distinction between pivotal construction and the other similar syntactic constructions.

\section{INTRODUCTION TO PIVOTAL CONSTRUCTION}

\section{A. Pivotal Construction}

Nowadays, most scholars agree with the term "pivotal constituent" to represent the Chinese syntactic term Jianyu, while the pivotal construction is the sentence with the construction of "pivotal constituent". The "the pivotal construction" is made up of a verb-object structure and a subject-predicate structure. There's no equivalent structure in English. So, when translated, the pivotal construction of the sentence is changed. Such a construction can be represented in a simple sentence in Chinese, whereas maybe a complex or simple sentence when translated into English.

E. g.1. He asks me to come. ( Ta Qing Wo Lai.)

In this sentence, "me" is the object of "ask" and it is also the logical subject of "come", and this structure is generally derived as $\mathrm{N}_{1}+\mathrm{V}_{1}+\mathrm{N}_{2}+\mathrm{V}_{2}$, which is a typical derivation of pivotal construction. $\mathrm{N}_{1}$ is the subject of the sentence. $\mathrm{V}_{1}$ $+\mathrm{N}_{2}+\mathrm{V}_{2}$ is termed as "pivotal constituent", in which $\mathrm{V}_{1}+\mathrm{N}_{2}$ is a verb-object structure and $\mathrm{N}_{2}+\mathrm{V}_{2}$ is a subject-predicate structure. These two structures are combined by $\mathrm{N}_{2}$, the pivotal noun, and also called "Jianyu" in Chinese, which means an element undertaking two syntactic functions without any inflectional change of the word form. So, $\mathrm{N}_{2}$ has two functions: the object of $\mathrm{V}_{1}$, and subject of $\mathrm{V}_{2}$. And $\mathrm{V}_{1}$ is the pivotal verb, governing $\mathrm{N}_{2}$ and having little semantic relation with $V_{2}$. According to Cui \& Sheng (1990), two aspects are the points of focus. The first is the causative meaning of $\mathrm{V}_{1}$, which involves certain object and makes the object behave in a certain way. The second aspect is about the two verbs. There is a logical connection of cause and effect relationship between $V_{1}$ and $V_{2}$. In their paper, the study of this construction is the study of $V_{1}$ and $V_{2}$. There are also a lot of studies on pivotal construction in Chinese academic circle, and they mainly focus on the naming process, deep structure analysis, classification and acquisition by foreign learners.

\section{B. Literature Review on Pivotal Construction}

How to name this pivotal construction once was a heated topic among scholars. At the beginning of the argument, Lv (1953) referred to this sentence pattern as "predicate form", while the "pivotal form" was proposed in the Modern Chinese Grammar Speech compiled by Ding etc.(1961) for the first time. After that, telescopic form, recursive sentence

\footnotetext{
* This research is supported by Humanities \& Social Sciences Project of Ministry of Education in China (Grant No. 13YJC740094). This research is also supported by Humanities \& Social Sciences Project of Educational Commission of Henan Province in China (Grant No. 2018-ZZJH-429).
} 
pattern, complex predicate, bi-functional constituent construction, Jianyu structure, etc. have appeared for a while. Whatever the name was, since people became aware of this linguistic phenomenon, scholars have carried on numerous researches on its attribution, category, definition and classification. However, some scholars have always questioned its existence and wish to put it into other sentence patterns. Shi (1954) is one of the earliest scholars who questioned "pivotal form". He believes both the telescopic form and the recursive structure sentences are the subject predicate complement structures in which the second verb and its subsequent components are the supplementary clause. In the Dispute on the Abolition of the Telescopic Form, Yang (1984) analyzes the similarities and differences between conceptual and grammatical functions of $\mathrm{N}$ in further detail, dividing the relationship between $\mathrm{V}_{1}$ and $\mathrm{V}_{2}$ into four types where $\mathrm{V}_{2}$ can be classified as an adverbial, object, complement of $\mathrm{V}_{1}$, or as the predicate of another clause. Although he does not directly deny the concept of the pivotal sentence, he holds the view that the existing definition of "pivotal sentence" is not clear enough and needs more advanced grammar framework to analyze. Ding (2006) totally discarded the proposition of "pivotal sentence". He ranked the multi-predicate sentences, such as pivotal sentences and predicate sentences, into multi-nucleus sentences. This classification can temporarily solve the disputes over pivotal sentence, however, the definition of multi-nucleus sentence is ambiguous and goes against the systemic analysis and acquisition of the sentence structure under the circumstance of diversification and internationalization of Chinese. In Su's research (2012), the traditional view of "Jiānyǔ Sentence Patterns" has serious theoretical flaws. And her study has presented an incisive analysis on the theoretical weaknesses of this view. She has proposed that the label of "Jiānyŭ Sentence Patterns" should be removed from mandarin grammar. By implementing the construction-chunk approach, her research introduced an alternative, demonstrating that the so-called "Jiānyŭ" sentences, some "double object sentences" and some "verb-predicate sentences with subject-predicate phase used as an object" are indeed seven different constructions: Request Construction, Causative Relation Construction, Action Permission Construction, Quality Judgment Construction, Position Explanation Construction, Action Collaboration Construction, and a subtype of Existential Construction.

Although views are widely different, now the majority of scholars agree on the existence of "pivotal form", which is an irrefutable fact after all. Along with the wide application of TG grammar, the research of pivotal sentence has a new start. Trying to redefine and reanalyze this special construction, scholars realized the existence of empty category, represented by "e", and the syntactic structure is $\mathrm{N}_{1}+\mathrm{V}_{1}+\mathrm{N}_{2}+\mathrm{e}+\mathrm{V}_{2}$ (Yang, 2006). Major disputes focus on the classification of the empty category. Xing (2004) claimed that, under the concept of "empty category" in Government and Binding Theory, the constituent $\mathrm{N}_{2}$ in pivotal form is the object of $\mathrm{V}_{1}$ and also is the patient argument, and there should be an empty subject of $\mathrm{V}_{2}$, i.e. PRO should be the agent argument. Yang (2006) has found out that the empty category in pivotal sentences can be divided into empty pronoun PRO and NP trace, which is different from the other scholars' conclusion. In different pivotal sentence patterns, the distribution of empty category is different and the same is true to the syntactic features. You (2002) classified pivotal verbs into 11 types and analyzed each type according to the semantic meaning. He believes the features of pivotal verbs, all containing causative meaning, are determined by the number and position of the obligatory arguments and themes and the available arguments and themes. This is helpful to define the features of pivotal verbs and distinguish pivotal sentence pattern and other sentence patterns under the guidance of thematic theory and argument structure analysis. Wen \& Yuan (2009) explored the derivation of the pivotal construction $\mathrm{NP}_{1}+\mathrm{VP}_{1}+\mathrm{NP}_{2}+\mathrm{VP}_{2}$ in the light of the "movement theory of control" and the "copy theory of movement". $\mathrm{NP}_{2}$, the pivotal constituent, merges at the subject position of $\mathrm{VP}_{2}$ and takes the Agent role. Since $\mathrm{VP}_{2}$ projects into $T_{\text {def }} P$, which fails to project into $C P$, a phase, $N_{2}$ can be probed by $V_{1}$ when the $T_{\text {def }} P$ merges with $V_{1}$. After feature checking, a copy of $\mathrm{NP}_{2}$ merges at the object position of $\mathrm{VP}_{1}$, receving the Accusative Case and the Theme $\theta$-role.

In recent years, some scholars have also studied the acquisition of pivotal construction from the perspective of teaching Chinese as a foreign language. Aiming to improve teaching strategies, Zhang (2002) analyzed the reasons that influence the correct use of "make" in pivotal sentences. In A Study on the Phonetic Segmentation of Chinese Language Teaching (2004), Wang and Jiang studied the segmentation of pivotal construction from the phonological aspect to seek for the difference from the other constructions. On the basis of the large-scale corpus statistics, Zhou (2009) analyzed the correct and erroneous usage of the foreign students and native users, and reached a conclusion about the error frequency. Whereas, he didn't explain the problems he had found, such as the difference of acquisition sequence of different types of pivotal construction, the influence of the deep structure on the acquisition sequence, and the reasons if the errors in learning process. Recently, there are some MA theses analyzing the acquisition of pivotal constructions (Li, 2010; Ma, 2011; Qu, 2013). The same as Zhou (2009), they all focus on the classification of errors, acquisition sequence, or the investigation on the degree if difficulty, paying less attention to the relationship between the deep structure and acquisition of pivotal construction.

\section{The Differentiation Between Pivotal Construction AND Similar Constructions}

The pivotal construction can be abbreviated as $\mathrm{N} 1+\mathrm{V} 1+\mathrm{N} 2+\mathrm{V} 2$ as mentioned in the first part. However, there are also many other sentences in Chinese which can be abbreviated in this way, just as the following examples:

E.g. 2. He knows I'm coming. (Subject-predicate structure as the object construction)

E.g. 3. He goes to the restaurant to eat. (The serial predicate construction) 
E.g. 4. He asks me to eat. (The fused serial predicate and pivotal construction)

The above sentences are all structures of $\mathrm{N} 1+\mathrm{V} 1+\mathrm{N} 2+\mathrm{V} 2$ in Chinese, which seem to be the same structure in pivotal construction. However, they belong to different syntactic constructions. Therefore, the aim of this paper is to make a detailed comparative analysis of the differences between them and the pivotal sentence as shown in E.g. 1. in the first part.

\section{A. The Distinction between Pivotal Construction and Subject-predicate Structure as the Object Construction}

In a sentence with subject-predicate structure as the object construction which is served as a set of the subject-predicate structure, as E.g. 2 "He knows I'm coming" where the object is "I'm coming" rather than "I". However, the pivotal construction in E.g. 1 "He asks me to come", the object of "asks" is "me", and "asks" is not directly related to "come" ("I" and "me" are the same word in Chinese). This syntactic structure is the most important difference between the two constructions. That is, in pivotal construction, $\mathrm{V}_{1}$ governs $\mathrm{N}_{2}$, not $\mathrm{V}_{2}$; while in the subject-predicate structure as the object construction, $\mathrm{V}_{1}$ governs both $\mathrm{N}_{2}$ and $\mathrm{V}_{2}$. The reason of the different functions of $\mathrm{V}_{1}$ in two construction lies in the semantic connotations.

From the aspect of semantic relation, the meaning of $\mathrm{V}_{1}$ is different in the two constructions. The pivotal verb $\mathrm{V}_{1}$ mainly contains the causative verb, that is to cause $\mathrm{N}_{2}$ generate the action of $\mathrm{V}_{2}$. However, in the subject-predicate structure as the object construction, $\mathrm{V}_{1}$, a verb that perceives and expresses emotions, receives the common effect generated by $\mathrm{N}_{2}$ and $\mathrm{V}_{2}$ together from the external or internal senses. So, it governs both $\mathrm{N}_{2}$ and $V_{2}$. A detailed classification of $\mathrm{V}_{1}$ is as follows:

According to the study of You (2002), the pivotal verbs in this paper can be divided into six types according to their semantic meanings:

(1) Causative: make, ask, let, order, want, find, cause, persuade, use, call, organize, arouse

(2) Order: order, prohibit, arrange, distribute, introduce, appoint, assign, request, command

(3) Advise: encourage, request, advise, exhort, notify, tell, urge, teach, prevent, spur, educate, train

(4) Authorize: authorize, entrust, request, beg, and demand

(5) Elective: recommend, elect, nominate, allot, call, name...after

(6) Recommend: Recommend, select, nominate, transfer, call, name......after

$\mathrm{V}_{1}$ in the subject-predicate phrase as the object construction mainly includes two categories:

(1) Perceptions: know, learn, hear, see, consider, think, perceive, feel

(2) Emotions: like, dislike, hate, worship, grumble, complain, cold-shoulder, afraid, blame

\section{B. The Distinction between Pivotal Construction and Serial Predicate Construction}

The serial predicate construction refers to a simple sentence which contains two or more than two verbs as predicates (only two-verb predicates are discussed here). In E.g. 3, "He goes to the restaurant to eat.", $\mathrm{V}_{1}$ "goes" and $\mathrm{V}_{2}$ "eat" are the actions of subject $\mathrm{N}_{1}$ "He", which is unrelated to $\mathrm{N}_{2}$ "restaurant". But in pivotal construction E.g. 1, $\mathrm{N}_{2}$ is the pivotal noun, playing an important role in the occurrence of $\mathrm{V}_{2}$. In other words, there are a lot of predicates in serial predicate construction, and all the predicates describe the same subject, while in pivotal construction, the subject of $\mathrm{V}_{1}$ and $\mathrm{V}_{2}$ are clearly different.

From the aspect of semantic relationship, in "He goes to the restaurant to eat.", "eat" is the purpose of "go". In order to eat, he goes to the restaurant. In fact, there are many kinds of relations between two verbs in the serial predicate construction, such as sequence, causation, and complementary relations etc. Due to the diversity of the relationship between $\mathrm{V}_{1}$ and $\mathrm{V}_{2}$, the classification of $\mathrm{V}_{1}$ becomes very difficult and most verbs can be used in the serial predicate construction. So the verbs used in this construction is not classified here.

\section{The Distinction between Pivotal Construction and Fused Serial Predicate and Pivotal Construction}

The structure of $\mathrm{N}_{1}+\mathrm{V}_{1}+\mathrm{N}_{2}+\mathrm{V}_{2}$ in the fused serial predicate and pivotal construction cannot be clearly divided into a certain structure. It is neither the serial predicate construction, nor the pivotal construction, and the two constructions are fused or combined by a specific semantic relationship. The verb $\mathrm{V}_{1}$ in E.g. 4, "He asks me to eat", although "ask" is a pivotal verb, there is a very special context here: to ask sb. to eat. In China, we have the consensus that if A asks B to eat, that means they will eat together, unless A specifically says he won't eat together. In other words, in this example, "he" and "I" will eat together. $\mathrm{N}_{1}$ is the subject of $\mathrm{V}_{1}$ and $\mathrm{V}_{2}$, and $\mathrm{N}_{2}$ is the logical subject of $\mathrm{V}_{2}$.

If this example is a pivotal construction, there is no semantic relation between $\mathrm{N}_{1}$ "he" and $\mathrm{V}_{2}$ "eat": "he" will not "eat". If it is the serial predicate construction, there is no semantic relation between $\mathrm{N}_{2}$ "me" and $\mathrm{V}_{2}$ "eat": "I" will not "eat". However, $\mathrm{N}_{1}$ is the subject of $\mathrm{V}_{1}$ and also the subject of $\mathrm{V}_{2}$, and $\mathrm{N}_{2}$ is also the agent of $\mathrm{V}_{2}$. That is, there are two logic subjects of $\mathrm{V}_{2}$, so as to meet the requirement of the serial predicate construction, and the pivotal construction. Therefore, the structure becomes independent and is named after the two constructions as fused serial predicate and pivotal construction, where the meaning of $\mathrm{V}_{1}$ is the key of this structure, so $\mathrm{V}_{1}$ caused $\mathrm{N}_{1}$ and $\mathrm{N}_{2}$ together to produce $\mathrm{V}_{2}$. Therefore these words mainly exist in the word with the meaning "accompany", and are classified as follows (Zhang, 1999):

(1) Lead: lead, take, guide, draw, command, arouse, show, pull, call, convene

(2) Accompany: accompany, escort, follow, show, company, follow, convoy, deliver, carry, chaperonage, coordinate 
(3) Help: help, assist, aid, support, and boost

\section{CONCLUSION}

From the above, it is clear that the pivotal construction can be expressed as $\mathrm{N}_{1}+\mathrm{V}_{1}+\mathrm{N}_{2}+\mathrm{V}_{2}$, but this structure can represent many similar constructions in Chinese. How to distinguish them mainly depends on the syntactic and semantic relations between the various components. The following tables are more intuitive displays of the four kinds of constructions respectively, of which the first row and the first vertical column are the four components $\mathrm{N}_{1}, \mathrm{~V}_{1}, \mathrm{~N}_{2}$ and $\mathrm{V}_{2}$. The components in horizontal row go first when analyzed. For example, the relationship between $\mathrm{N}_{1}$ and $\mathrm{V}_{1}$ in Table 1 is subject-predicate relation, which has a sequence and $\mathrm{N}_{1}$ goes first. This sequence can not be changed as $\mathrm{V}_{1}$ and $\mathrm{N}_{1}$, or the relationship will be changed into "verb-object". That is the same to $\mathrm{V}_{1}$ and $\mathrm{N}_{2}$, verb-object relation. If " $\mathrm{N}_{2}$ and $\mathrm{V}_{1}$ " is used, that refers to a subject-predicate relation. The relation of $\mathrm{V}_{1}$ and $\mathrm{V}_{2}$ is mostly causative. $\mathrm{N}_{2}$ and $\mathrm{V}_{2}$ is subject-predicate relation.

TABLE 1.

SYNTACTIC RELATION IN PIVOTAL CONSTRUCTION

\begin{tabular}{|l|l|l|l|l|}
\hline & $\mathrm{N}_{1}$ & $\mathrm{~V}_{1}$ & $\mathrm{~N}_{2}$ & $\mathrm{~V}_{2}$ \\
\hline $\mathrm{N}_{1}$ & & & & \\
\hline $\mathrm{V}_{1}$ & subject-predicate & & & \\
\hline $\mathrm{N}_{2}$ & & verb-object & & \\
\hline $\mathrm{V}_{2}$ & & causative & Subject-predicate & \\
\hline
\end{tabular}

TABLE 2.

SYNTACTIC RELATION IN SUBJECT-PREDICATE STRUCTURE AS THE OBJECT CONSTRUCTION

\begin{tabular}{|c|c|c|c|c|}
\hline & $\mathrm{N}_{1}$ & $\mathrm{~V}_{1}$ & $\mathrm{~N}_{2}$ & $\mathrm{~V}_{2}$ \\
\hline $\mathrm{N}_{1}$ & & & & \\
\hline $\mathrm{V}_{1}$ & subject-predicate & & & \\
\hline $\mathrm{N}_{2}$ & & & & \\
\hline $\mathrm{V}_{2}$ & & \multirow{2}{*}{$\begin{array}{l}\text { (interb-object } \\
\text { perception) }\end{array}$} & & \\
\cline { 3 - 5 } & & subject-predicate & \\
\hline
\end{tabular}

TABLE 3.

SYNTACTIC RELATION OF SERIAL PREDICATE CONSTRUCTION

\begin{tabular}{|l|l|l|l|l|}
\hline & $\mathrm{N}_{1}$ & $\mathrm{~V}_{1}$ & $\mathrm{~N}_{2}$ & $\mathrm{~V}_{2}$ \\
\hline $\mathrm{N}_{1}$ & & & & \\
\hline $\mathrm{V}_{1}$ & subject-predicate & & & \\
\hline $\mathrm{N}_{2}$ & & & & \\
\hline $\mathrm{V}_{2}$ & subject-predicate & $\begin{array}{l}\text { precedence, purpose, } \\
\text { consequence, complementary }\end{array}$ & & \\
\hline
\end{tabular}

TABLE 4.

SYNTACTIC RELATION OF FUSED SERIAL PREDICATE AND PIVOTAL CONSTRUCTION

\begin{tabular}{|l|l|l|l|l|}
\hline & $\mathrm{N}_{1}$ & $\mathrm{~V}_{1}$ & $\mathrm{~N}_{2}$ & $\mathrm{~V}_{2}$ \\
\hline $\mathrm{N}_{1}$ & & & & \\
\hline $\mathrm{V}_{1}$ & subject-predicate & & & \\
\hline $\mathrm{N}_{2}$ & & verb-object & & \\
\hline $\mathrm{V}_{2}$ & subject-predicate & lead, accompany, help & subject-predicate & \\
\hline
\end{tabular}

From the above tables, it can be summarized, in the pivotal construction, the relationship of $\mathrm{N}_{1}$ and $\mathrm{V}_{1}$ is subject-verb, $\mathrm{V}_{1}$ and $\mathrm{N}_{2}$ is verb-object, $\mathrm{N}_{2}$ and $\mathrm{V}_{2}$ is logical subject-verb, and $\mathrm{V}_{1}$ and $\mathrm{V}_{2}$ is in cause-effect relation, and $\mathrm{V}_{1}$ brings on the action of $\mathrm{V}_{2}$. So the complex relations among the four components $\mathrm{N}_{1}, \mathrm{~V}_{1}, \mathrm{~N}_{2}$, and $\mathrm{V}_{2}$ are crucial to the distinction of the four syntactic constructions.

In Table 2, the relation of $N_{1}$ and $V_{1}$ is subject-predicate. $V_{1}$ has a relation with $N_{2}$ and $V_{2}$ at the same time, and $V_{1}$ is not related to $\mathrm{N}_{2}$ or $\mathrm{V}_{2}$ respectively. So the function of $\mathrm{N}_{2}$ and $\mathrm{V}_{2}$ as a whole is the object of $\mathrm{V}_{1}$, that is the verb-object relation. The relation of $\mathrm{N}_{2}$ and $\mathrm{V}_{2}$ is logical subject-predicate. $\mathrm{V}_{1}$ perceives the existence of $\mathrm{N}_{2}+\mathrm{V}_{2}$ as its object through internal or external senses.

In Table 3, the serial predicate construction, the relation of $\mathrm{N}_{1}$ and $\mathrm{V}_{1}$ is subject-predicate. The relation of $\mathrm{N}_{1}$ and $\mathrm{V}_{2}$ is also subject-predicate. There is no relation between $V_{1}$ and $N_{2}, N_{2}$ and $V_{2} \cdot V_{1}$ and $V_{2}$ are the actions issued by the subject, which can be in sequential order, objective relation, cause-effect relation, and complementary relation, etc.

In Table 4 , the relation of $N_{1}$ and $V_{1}$ is subject-predicate. $N_{1}$ and $V_{2}$ is logical subject-predicate relation. $N_{2}$ is the object of $V_{1} . N_{2}$ is the subject of $V_{2}$. The relation between $V_{1}$ and $V_{2}$ is the interaction about leading, accompanying and helping.

By now, the four constructions are analyzed thoroughly and the boundary between them seems very clear. It is concluded that the syntactic relations of the four components $\mathrm{N}_{1}, \mathrm{~V}_{1}, \mathrm{~N}_{2}$ and $\mathrm{V}_{2}$ are complex in each construction. On the semantic level, the meaning of $\mathrm{V}_{1}$ and the relation between $\mathrm{V}_{1}$ and $\mathrm{V}_{2}$ are of vital importance to differentiate these four constructions.

However, there is always exception: 
E.g. 5. Xiaoming helps mom sweep.

There are two explanations for this sentence. Xiaoming can sweep the floor with his mother, or he sweeps the floor alone instead of his mother. If it is the former situation, this sentence belongs to the third type, the fused serial predicate and the pivotal construction; if it is the latter, this sentence is the serial predicate construction. To make clear the exact meaning of this sentence, the specific context must be taken into consideration.

Anyway, the conclusion of this paper is very useful when we come across the four typical constructions in Chinese. And the relation of the four components in each construction can be reduced to the relation between $V_{1}$ and $V_{2}$. If $V_{1}$ and $\mathrm{V}_{2}$ is in cause-effect relation, and $\mathrm{V}_{1}$ brings on the action of $\mathrm{V}_{2}$, then it is the pivotal construction. If $\mathrm{V}_{1}$ has a relation with $\mathrm{N}_{2}$ and $\mathrm{V}_{2}$ as a whole, it is subject-predicate structure as the object construction. If $\mathrm{V}_{1}$ and $\mathrm{V}_{2}$ are the actions issued by the subject, it is the serial predicate construction. If the relation between $V_{1}$ and $V_{2}$ is the interaction about leading, accompanying and helping, it is the fused serial predicate and pivotal construction.

This shows the free variation of the semantic relations among Chinese verbs and it is really difficult for a learner of Chinese language to learn it well. But if a foreigner can master the differences mentioned above, it is much helpful for him to use the verbs freely and reduce errors to a certain extent.

\section{REFERENCES}

[1] Cui Yingxian \& Sheng Yongsheng. (1990). A Brief Discussion on "Jianyu Structure”, Journal of Henan Normal University, 3 , 52-56.

[2] Ding Li. (2006). Queries on Pivotal Construction and Serial Predicate Construction--Comments on Multi-nucleus Sentences, Cultural and Educational Information, 9, 107-108.

[3] Ding Shengshu. (1961). Modern Chinese Grammar Speech. Beijing: Commercial Press.

[4] Li Yufei. (2010). Error Analysis of the 'Jianyu' Sentences Aiming at Overseas Students. M.A. thesis, East China Normal University.

[5] Lv Shuxiang. (1953). Grammar Learning. Beijing: China Youth Press.

[6] Ma Wenjia. (2011). The Acquisition and Error Analysis of Jianyu Structure by Foreign Students. M.A. thesis, Northwest University.

[7] Qu Shuhong. (2013). The Study of Thai Students Acquisition of Pivotal Construction. M.A. thesis, Guangxi University.

[8] Shi Cunzhi. (1954). Study on the Delivery System and Telescopic Form. Chinese language, 3, 5-8.

[9] Su Danjie. (2012). Removing the Label of "Jiānyŭ Sentence Patterns" from Mandarin Grammar: The Construction-Chunk Approach to an Alternative. Studies in Language and Linguistics, 32, 100-107.

[10] Wang Lixiang \& Jiang Hailing. (2004). A Study on the Phonetic Segmentation of Chinese Language Teaching. Journal of Yunnan Normal University, 7, 35-39.

[11] Wen Binli \& Yuan Fang. (2009). The Derivation of the Bi-Functional Constituent Construction in Chinese. Journal of Foreign Languages, 32, 2-10.

[12] Xing Xin. (2004). Pivotal Structure in Modern Chinese. Beijing: Beijing Broadcasting Institute Press.

[13] Yang Chengkai. (1984). Dispute on the Abolition of the Telescopic Form. Learning and Thinking, 1, 64-69.

[14] Yang Daran. (2006). Semantic Classification and Syntactic Distribution of Empty Categories in the Chinese Bi-constituent Sentences. Journal of PLA University of Foreign Languages, 1, 23-28.

[15] You Rujie. (2002). Syntactic and Semantic Features of the Pivotal Sentence in Modern Chinese. Chinese Learning, 6, 1-6.

[16] Zhang Yong. (1999). On the Classification of the Fused Serial Predicate and Pivotal Construction. Journal of Liaoning University, 3, 25-27.

[17] Zhang Xinming. (2002). Teaching Strategies of Guiding Students Abroad to Construct Sentences including "Shi”. Journal of Wuxi Vocational Institute of Commercial Technology, 4, 52-54.

[18] Zheng Ji'e. (1996). Serial Predicate Construction and Pivotal Construction of the Inscriptions on Oracle Bones. Journal of Ancient Chinese Study, 2, 29-31.

[19] Zhou Wenhua. (2009). A Corpus-based Study on the Acquisition of Pivotal Construction. Journal of Language Teaching and Research, 3, 40-47.

Zhiyan Hu (1981-), born in Xinxiang, Henan Province, China, is a lecturer in the Faculty of Foreign Languages in Xinxiang Medical University. She has taught many courses in English major, and her research area is Applied Linguistics. 